\title{
Mortality and Attrition Rates within the First Year of Antiretroviral Therapy Initiation among People Living with HIV in Guangxi, China: An Observational Cohort Study
}

\author{
Jinhui Zhu $\left(\mathbb{D},{ }^{1}\right.$ Mohammed Adnan Yousuf, ${ }^{2}$ Wenmin Yang, ${ }^{1}$ Qiuying Zhu, ${ }^{1}$ Zhiyong Shen, \\ Guanghua Lan, ${ }^{1}$ Yi Chen, ${ }^{1}$ Huanhuan Chen, ${ }^{1}$ Wensheng Fan, ${ }^{3}$ Hui Xing, ${ }^{1,4}$ Yiming Shao, ${ }^{1,4}$ \\ Yuhua Ruan, ${ }^{1}$ and Liming $\mathrm{Li} \mathbb{D}^{5}$ \\ ${ }^{1}$ Guangxi Center for Disease Control and Prevention, Nanning, China \\ ${ }^{2}$ Department of Public Health, Western Kentucky University, Bowling Green, KY, USA \\ ${ }^{3}$ Department of Health Services Administration, Florida International University, Miami, FL, USA \\ ${ }^{4}$ State Key Laboratory of Infectious Disease Prevention and Control (SKLID), Collaborative Innovation Center for Diagnosis and \\ Treatment of Infectious Diseases, Chinese Center for Disease Control and Prevention (China CDC), Beijing, China \\ ${ }^{5}$ School of Public Health, Peking University, Beijing, China
}

Correspondence should be addressed to Liming Li; lmlee@vip.163.com

Received 12 October 2020; Revised 14 January 2021; Accepted 21 January 2021; Published 11 February 2021

Academic Editor: Bin Su

Copyright (C) 2021 Jinhui Zhu et al. This is an open access article distributed under the Creative Commons Attribution License, which permits unrestricted use, distribution, and reproduction in any medium, provided the original work is properly cited.

Objective. To assess the mortality and attrition rates within the first year of antiretroviral therapy (ART) initiation among people living with human immunodeficiency virus (PLHIV) in rural Guangxi, China. Design. Observational cohort study. Setting. The core treatment indicators and data were collected with standard and essential procedures as per the Free ART Manual guidelines across all the rural health care centers of Guangxi. Participants. 58,115 PLHIV who were under ART were included in the study. Interventions. The data collected included sociodemographic characteristics that consist of age, sex, marital status, route of HIV transmission, CD4 cell count before ART, initial ART regimen, level of ART site, and year of ART initiation. Primary and Secondary Outcome Measures. Mortality and attrition rate following ART initiation. Results. The average mortality rate was 5.94 deaths, and 17.52 attritions per 100 person-years within the first year of ART initiation among PLHIV. The mortality rate was higher among intravenous drug users (Adjusted Hazard Ratio (AHR) 1.27, 95\% Confidence Interval (CI) 1.14-1.43), prefecture as a level of ART site (AHR 1.14, 95\% CI 1.02-1.28), and county as the level of ART site (AHR 2.12, 95\% CI 1.90-2.37). Attrition was higher among intravenous drug users (AHR 1.87, 95\% CI 1.75-2.00), the first-line ART containing AZT (AHR 1.09, 95\% CI 1.03-1.16), and first-line ART containing LVP/r (AHR 1.34, 95\% CI 1.23-1.46). Conclusion. The mortality and attrition rates were both at the highest level in the first year of post-ART; continued improvement in the quality of HIV treatment and care is needed.

\section{Introduction}

HIV infection in China began as a drug-driven epidemic among injection drug users, and with time, it shifted to the mainly sexual route $[1,2]$. By the end of 2015 , a total of 577,423 individuals were living with HIV in China [3]. It is estimated that new cases of HIV epidemic scale up to 50,000 individuals annually [4], irrespective of China's National Free Antiretroviral Treatment Program (NFATP) that began in 2003 [5]. NFATP is a community-based public health program that helped to reduce the mortality rate among HIV-infected individuals in China [6, 7]. It develops in three phases. Initiation was from 2003 to 2005 . The threshold for the NFATP in 2003 was CD4+ T cell counts less than 200 cells $/ \mu \mathrm{L}$. [8] The first scale-up was from 2005 to 2008 . The ART threshold was raised to $\mathrm{CD} 4+\mathrm{T}$ cell counts less than 350 cells $/ \mu \mathrm{L}$, and further scale-up and standardization were from 2009 to 2011 . It rapidly expanded the treatment 
for prevention from 2012 to 2015; ART has been initiated regardless of CD4+ T cell counts [9-11].

According to Tang et al., by 2015 in China, 382,139 PLHIV have received Antiretroviral Therapy (ART) [12]. This rapid expansion of ART has further resulted in a drastic reduction in mortality among $\mathrm{HIV}$-infected individuals, while this mortality rate remains much higher than in developed countries [13,14]. Nevertheless, some HIV-infected patients might not have been aided by ART because of the limited access to care in resource-limited areas and also attrition of the patients after ART initiation $[15,16]$. Thus, attrition during ART regimen is associated with progression of HIV to AIDS, treatment failure, drug resistance, and even mortality [4]. Although there are achievements by China's NFATP, high-quality evidence is needed to better understand mortality and attrition rates within the early year of ART initiation among Chinese PLHIV that can help with continuing improvements in the quality of HIV treatment and care.

Guangxi is located on the southern coast of China. The reported numbers of HIV cases in Guangxi are estimated to be $10 \%$ of the total reported cases in China, which is the highest number of HIV cases in China [1, 17]. The objective of this research is to assess the mortality and attrition rates within the first year of ART initiation among PLHIV in Guangxi.

\section{Materials and Methods}

2.1. Patient and Public Involvement. Since the study is retrospective, patients or the public were not involved in the design or in the conduct of the study.

2.2. Study Design and Study Population. This observational cohort was conducted in the rural areas of Guangxi, in southwest China. The cohort profile and characteristics of this database have been previously described $[8,10,16]$. The data were collected from 2003 to 2015. The eligibility criteria for the participants were 18 years or older, HIV-positive patients, recipient of first-line ART at any point between 2003 and 2015, willingness, and those who provide written consent for the study. It has $64 \%$ of participants still in follow-up. The study was approved by the institutional review board of the Guangxi Center for Disease Control and Prevention (reference number for the ethics committee to this manuscript is GXIRB2016-0047).

Attrition was defined as a cessation of ART or loss to follow-up as recorded in the HIV treatment database [18]. Lost to follow-up was defined as missing more than 90 days after the last date seen in the clinic, which was also defined as the date of withdrawal $[10,12]$.

2.3. Treatment Regimen and Criteria. China recommended first-line HAART regimen as per the WHO guidelines. First-line HAART regimens before 2008 consisted of (zidovudine $(\mathrm{AZT})$ or stavudine $(\mathrm{D} 4 \mathrm{~T}))+($ didanosine $(\mathrm{DDI})$ or lamivudine $(3 \mathrm{TC}))+($ nevirapine $(\mathrm{NVP})$ or efavirenz $(\mathrm{EFV}))$ $[8,9]$. Zidovudine, stavudine, didanosine, and nevirapine are generically produced in China and were standard pre- scriptions since the start of the program in 2003, whereas lamivudine and efavirenz are branded drugs that became available in 2005 [19] and gradually became more commonly prescribed following preferential use in those with strong adverse reactions to the former standard regimens. The first-line ART regimen in the second edition National Free ART Guideline in 2008 was revised to consist of (tenofovir (TDF) or azidothymidine (AZT) ) + lamivudine (3TC) + (efavirenz (EFV) or nevirapine (NVP)). The NFATP treatment criteria included CD4 $+\mathrm{T}$ cell counts less than 200 cells $/ \mu \mathrm{L}$ from 2003 to 2008 , CD4+ T cell counts less than 350 cells $/ \mu \mathrm{L}$ from 2008 to 2012, and starting 2012, ART has been initiated irrespective of CD4+ T cell counts. According to the recent WHO guidelines, ART is recommended immediately for all HIV infected patients irrespective of CD4 cell count [20]. Before treatment initiation, PLHIV were given free education and counseling on the importance of ART and adherence. The initial treatment regimen and criteria could be associated with treatment effects [9].

2.4. Data Collection. Variables of the PLHIV who received ART included baseline characteristics of age, sex, marital status, route of HIV transmission, CD4 cell count before ART, initial ART regimen, level of ART site, and year of ART initiation. HIV infection status was determined by an enzyme immunoassay (EIA) and an HIV-1/2 Western blot confirmation. It did not include self-reported. Treating physicians who provided the ART at the local medical centers managed the case reports forms at the time of initiating ART and follow-up at $0.5,1,2$, and 3 months and every 3 months afterwards. CD4 cell count was assessed at each follow-up. The case report forms were uploaded into a web-based database hosted by CDC, China. Follow-up variables were evaluated every 3 months after ART and included death or attrition. Variables collected at each follow-up included transferals to another clinic, cessation of ART, loss to follow-up, duration of ART, and survival status, which were collected from hospital records or having clinic doctors call family members to inquire about death. The date of death was based on death certificate information. The core treatment indicators and data were collected with a standard and essential procedures as per the Free ART Manual guidelines across all the health care centers.

2.5. Statistical Analysis. An observational cohort study was conducted using the Guangxi data from the NFATP. The outcomes of interest (mortality and attrition rates) following the first-line ART regimen drugs D4T, AZT, TDF, and LPV/r were obtained. Mortality and attrition rate cumulative incidence was calculated on the basis of Poisson distributions and as deaths and attrition per 100 person-years of followup. Time zero was defined as the date of ART initiation, and data was censored on June 30, 2016. Patients were censored if they were still alive or transferred to another clinic for care.

Cox proportional hazard models were used to evaluate treatment effects of initial ART regimen on death and attrition (cessation of ART or loss to follow-up) of the first year in PLHIV who started ART between 2003 and June 2015, 
respectively. Competing risks for cause-specific hazard models were censored accordingly. Cause-specific Cox proportional hazard models were used to assess the effects of CD4+ count levels before ART on attrition and death. To control for potential confounding, the following baseline variables were included: age, sex, marital status, route of HIV infection, initial ART regimen, level of ART site, and year of ART initiation. Variables were combined and analyzed with the Statistical Analysis System software (SAS 9.4 ${ }^{\mathrm{TM}}$ for Windows; SAS Institute Inc., Cary, NC, USA). $P$ value < 0.05 was regarded as statistically significant, and all tests were 2 sided. The results were presented with the adjusted hazard ratios (AHRs) and at 95\% CI.

\section{Results}

3.1. Characteristics. Of the 58,270 PLHIV who initiated ART between January 2003 and June 2015 in Guangxi, China, 147 patients were less than 18 years of age, and 8 patients had no any follow-up data after ART, so they were excluded from the study. A total of 5,822 patients within the first year of ART initiation lost to follow-up, and 3,125 patients stopped ART. Of the 3,125 patients who stopped ART, 1,244 (39.8\%) were due to poor adherence, 1,059 (33.9\%) were due to drug side effects, $65(2.1 \%)$ were due to economic issues, and 757 (24.2\%) were due to other reasons. Finally, a total of 58,115 eligible patients were included in this cohort study.

Table 1 shows the general characteristics of these patients. The majority (33.2\%) of the individuals belong to the $35-49$ years age group, $67.0 \%$ were males, and $69.2 \%$ were married or cohabitation. Of all the participants with sexually transmitted infection, $85.4 \%$ self-reported as heterosexual intercourse, $1.6 \%$ self-reported as homosexual, $10.2 \%$ received through intravenous drug use, and $2.8 \%$ as other routes. The CD4 cell count before initiation of ART was less than 200 cells $/ \mu \mathrm{L}$ for $59.8 \%$ individuals followed by 200 350 cells $/ \mu \mathrm{L}$ for $28.0 \%, 350-500$ cells $/ \mu \mathrm{L}$ in $7.8 \%$, equal to or more than 500 in $2.8 \%$, and missing $1.5 \%$. Under the initial ART regimen, the first-line ART containing D4T constitute $24.5 \%$, ART containing AZT was $39.7 \%$, ART containing TDF was $24.0 \%$, ART containing LPV/r was $7.8 \%$, and others were $4.0 \%$. Levels of ART site as provincial were $18.8 \%$, the prefecture was $38.8 \%$, and the county was $42.4 \%$. Because the threshold for the NFATP was changed, more and more PLHIV were involved in ART. The number of patients initiating ART raised from 13.3\% during the years 2003-2008 to $56.1 \%$ during 2012-2015.

3.2. Mortality Rates. Among all the HIV-infected participants who started ART between 2003 and 2015, there are 5,377 deaths; the average mortality rate was 2.96 deaths per 100 person-years among all participants. The mortality rate per 100 person-years was 5.94 in the first year of ART, and then, it decreased thereafter (Supplementary Table 1). Table 2 shows the mortality and attrition rates in PLHIV started ART between 2012 and 2015 in Guangxi.

Univariate Cox regression analyses indicated that several factors were significantly associated with mortality rate,
TABLE 1: Characteristics of PLHIV who started ART between 2003 and June 2015 in Guangxi, China.

\begin{tabular}{|c|c|c|}
\hline Variable & Number & $\%$ \\
\hline Total & 58,115 & - \\
\hline \multicolumn{3}{|l|}{ Age (years) } \\
\hline $18-34$ & 18,358 & 31.6 \\
\hline $35-49$ & 19,290 & 33.2 \\
\hline $50-70$ & 17,457 & 30.0 \\
\hline$\geq 70$ & 3,010 & 5.2 \\
\hline \multicolumn{3}{|l|}{ Sex } \\
\hline Male & 38,957 & 67.0 \\
\hline Female & 19,158 & 33.0 \\
\hline \multicolumn{3}{|l|}{ Marital status } \\
\hline Married or cohabitation & 40,224 & 69.2 \\
\hline Other & 17,891 & 30.8 \\
\hline \multicolumn{3}{|l|}{ Route of HIV transmission } \\
\hline Heterosexual intercourse & 49,608 & 85.4 \\
\hline Intravenous drug use & 5,954 & 10.2 \\
\hline Homosexual intercourse & 925 & 1.6 \\
\hline Other & 1,628 & 2.8 \\
\hline \multicolumn{3}{|l|}{ CD4 cell count (cells $/ \mu \mathrm{L}$ ) before ART } \\
\hline$<200$ & 34,774 & 59.8 \\
\hline $200-350$ & 16,252 & 28.0 \\
\hline $350-500$ & 4,550 & 7.8 \\
\hline$\geq 500$ & 1,648 & 2.8 \\
\hline Missing & 891 & 1.5 \\
\hline \multicolumn{3}{|l|}{ Initial ART regimen } \\
\hline The first-line ART containing D4T & 14,244 & 24.5 \\
\hline The first-line ART containing AZT & 23,059 & 39.7 \\
\hline The first-line ART containing TDF & 13,965 & 24.0 \\
\hline The first-line ART containing LPV/r & 4,510 & 7.8 \\
\hline Other & 2,337 & 4.0 \\
\hline \multicolumn{3}{|l|}{ Level of ART site } \\
\hline Provincial & 10,920 & 18.8 \\
\hline Prefecture & 22,525 & 38.8 \\
\hline County & 24,670 & 42.4 \\
\hline \multicolumn{3}{|l|}{ Year of ART initiation } \\
\hline 2003-2008 & 7,741 & 13.3 \\
\hline 2009-2011 & 17,800 & 30.6 \\
\hline $2012-2015$ & 32,574 & 56.1 \\
\hline
\end{tabular}

ART: antiretroviral therapy; D4T: stavudine; AZT: azidothymidine; TDF: tenofovir; LPV/r: ritonavir-boosted lopinavir; HR: hazard ratio; AHR: adjusted hazard ratio.

including age, sex, marital status, route of HIV infection, CD4 cell count (cells/ $\mu \mathrm{L}$ ) before ART, initial ART regimen, level of ART site, and year of ART initiation. In the multivariate model, factors associated with lower risk of mortality rate were female gender (AHR 0.55, 95\% CI 0.50-0.60), homosexual intercourse as HIV transmission route (AHR 0.50, 95\% CI 0.28-0.88), CD4 count 200-350 before initiation of ART (AHR 0.26, 95\% CI 0.23-0.30), CD4 count 350-500 (AHR 0.19; 95\% CI 0.14-0.25), CD4 count $\geq 500$ (AHR 0.17, 95\% 
TABLE 2: Mortality and attrition rates in PLHIV started ART between 2012 and June 2015 in Guangxi, China, by year post-ART initiation.

\begin{tabular}{lcccccc}
\hline Variable & Number & $\begin{array}{c}\text { Person- } \\
\text { years }\end{array}$ & Deaths & $\begin{array}{c}\text { Deaths per 100 person-years (95\% } \\
\text { CI })\end{array}$ & Attritions & $\begin{array}{c}\text { Attritions per 100 person-years } \\
(95 \% \text { CI })\end{array}$ \\
\hline $\begin{array}{l}\text { Total } \\
\text { Year post-ART }\end{array}$ & 32,574 & $68,463.57$ & 1,913 & $2.79(2.67-2.92)$ & 7,438 & $10.86(10.62-11.10)$ \\
initiation & & & & & & \\
The first year & 32,574 & $28,659.32$ & 1,221 & $4.26(4.03-4.49)$ & 5,440 & $18.98(18.49-19.47)$ \\
The 2nd year & 26,046 & $24,937.71$ & 417 & $1.67(1.52-1.83)$ & 1,490 & $5.97(5.68-6.27)$ \\
The 3rd year & 16,274 & $15,815.86$ & 190 & $1.20(1.03-1.37)$ & 564 & $3.57(3.28-3.85)$ \\
The 4th year & 8,861 & $8,689.38$ & 83 & $0.96(0.75-1.16)$ & 201 & $2.31(2.00-2.62)$ \\
\hline
\end{tabular}

CI 0.10-0.27), the first-line ART containing AZT (AHR 0.53, 95\% CI 0.49-0.59), the first-line ART containing TDF (AHR $0.70,95 \%$ CI 0.62-0.79), other drugs (AHR 0.40, 95\% CI $0.32-$ 0.50 ), and year of ART initiation from 2009 to 2011 (AHR 0.77, 95\% CI 0.70-0.86) and from 2012 to 2015 (AHR 0.49, 95\% CI 0.43-0.55). The following are the factors associated with a higher risk of mortality rate: age group 35-49 years old (AHR 1.40, 95\% CI 1.26-1.55), age group 50-70 years old (AHR 1.95, 95\% CI 1.74-2.17), and equal to or more than 70 years (AHR 2.70, 95\% CI 2.31-3.15); other marital status (AHR 1.20, 95\% CI 1.11-1.30); route of HIV transmissio$\mathrm{n}$-intravenous drug use (AHR 1.27, 95\% CI 1.14-1.43); prefecture as the level of ART site (AHR 1.14, 95\% CI 1.02-1.28); and county as the level of ART site (AHR 2.12, 95\% CI 1.902.37) (Table 3). Similar study results were observed even after excluding individuals with missing baseline CD4 counts and PLHIV who started ART between 2003 and June 2011, respectively (Supplementary Table 2, Supplementary Table 3, and Supplementary Table 4).

3.3. Attrition Rates. Among all the HIV-infected participants who started ART between 2003 and 2015, 15,744 attritions were reported. The average attrition rate was 8.66 per 100 person-years among all participants. The attrition rate per 100 person-years was 17.52 in the first year of ART, and then, it decreased thereafter (Supplementary Table 2).

Univariate Cox regression analyses indicated that age, sex, marital status, route of HIV infection, CD4 cell count (cells $/ \mu \mathrm{L}$ ) before ART, initial ART regimen, level of ART site, and year of ART initiation were significantly associated with attrition rate. In the multivariate model, factors associated with lower risk of attrition rate were female gender (AHR 0.89, 95\% CI 0.85-0.94), homosexual intercourse as HIV transmission route (AHR 0.45, 95\% CI 0.35-0.58), the firstline ART containing TDF (AHR 0.81, 95\% CI 0.75-0.87), and other drugs (AHR 0.87, 95\% CI 0.76-1.00). The following are factors associated with a higher risk of attrition rate: age group 35-49years old (AHR 1.15, 95\% CI 1.09-1.22), followed by age group 50-70 years old (AHR 1.55, 95\% CI 1.46-1.64), equal to or more than 70 years (AHR 2.51, 95\% CI 2.30-2.73), other marital status (AHR 1.32, 95\% CI 1.261.38), route of HIV transmission-intravenous drug use (AHR 1.87, 95\% CI 1.75-2.00), CD4 count 350-500 before initiation of ART (AHR 1.11, 95\% CI 1.03-1.21), CD4 count $\geq 500$ (AHR 1.29, 95\% CI 1.15-1.45), the first-line ART con- taining AZT (AHR 1.09, 95\% CI 1.03-1.16), ART containing LPV/r (AHR 1.34, 95\% CI 1.23-1.46), and year of ART initiation from 2009 to 2011 (AHR 1.74, 95\% CI 1.60-1.91) and from 2012 to 2015 (AHR 1.90, 95\% CI 1.73-2.08). Table 4. Similar study results were observed even after excluding individuals with missing baseline CD4 counts (Supplementary Table 6 and Supplementary Table 7).

\section{Discussion}

With time, China's ART guidelines evolved as per the WHO recommendations [21]. And hence, this is one of the reasons in our study; we see a drastically high number of participants during the period 2012-2015 of ART initiation, besides increased awareness regarding treatment, and a high incidence of new HIV cases is reported annually [4].

The overall mortality rate was 2.96 per 100 person-years in HIV-infected patients who started ART from January 2003 to June 2015. It was at the peak of 5.94 per 100 person-years during the first year, lower than a Tanzanian study [22], and gradually reduced to 0.63 per 100 personyears at the end of the $11^{\text {th }}$ year of initiation of ART. The impact of ART has significantly reduced the mortality among PLHIV in this study. The scale-up and standardization of NFATP after 2008 has shown to be very successful in lowering the mortality rate in China [23]. Furthermore, the rapid expansion and treatment for prevention from 2012 had significantly lowered the mortality rate. However, according to WHO, the mortality rate is higher during the early months of ART as early adverse drug reactions, opportunistic infections, and/or immune reconstitution inflammatory syndrome may develop during that period. These complications are common in patients who initiate ART with advanced HIV, existing coinfections, malnourished individuals, very low CD4 cell counts, severely low hemoglobin, and low body mass index [24, 25]. However, some PLHIV might die early after receiving ART, due to several very sick and no complications.

The mortality rate of the first year in PLHIV who started ART is higher among aged patients. This is similar to a previous study conducted by HIV-Casual Collaboration [26]. (Supplementary Table 2). Older individuals have a poorer immunologic response and other aging-related problems like hypertension, hypertriglyceridemia, lipodystrophy, and low bone mineral density [27]. Also, females have a lower 
TABle 3: Mortality rate of the first year in PLHIV who started ART between 2003 and June 2015 in Guangxi, China.

\begin{tabular}{|c|c|c|c|c|c|c|c|c|}
\hline Variable & Number & Deaths & $\begin{array}{l}\text { Person- } \\
\text { years }\end{array}$ & $\begin{array}{l}\text { Deaths per } 100 \text { person-years } \\
(95 \% \mathrm{CI})\end{array}$ & $\begin{array}{l}\text { HR }(95 \% \\
\quad \text { CI })\end{array}$ & $P$ & $\begin{array}{l}\text { AHR }(95 \% \\
\text { CI })\end{array}$ & $P$ \\
\hline Total & 58,115 & 3,035 & $51,066.90$ & $5.94(5.74-6.15)$ & - & - & - & - \\
\hline \multicolumn{9}{|l|}{ Age (years) } \\
\hline $18-34$ & 18,358 & 684 & $16,591.47$ & $4.12(3.82-4.42)$ & Reference & & Reference & \\
\hline $35-49$ & 19,290 & 974 & $17,079.86$ & $5.70(5.35-6.05)$ & $\begin{array}{l}1.38(1.25- \\
1.52)\end{array}$ & $\begin{array}{c}< \\
0.001\end{array}$ & $\begin{array}{l}1.40(1.26- \\
1.55)\end{array}$ & $\begin{array}{c}< \\
0.001\end{array}$ \\
\hline $50-70$ & 17,457 & 1,091 & $15,016.71$ & $7.27(6.84-7.69)$ & $\begin{array}{l}1.74(1.58- \\
1.91)\end{array}$ & $\begin{array}{c}< \\
0.001\end{array}$ & $\begin{array}{l}1.95(1.74- \\
2.17)\end{array}$ & $\begin{array}{c}< \\
0.001\end{array}$ \\
\hline$\geq 70$ & 3,010 & 286 & $2,378.87$ & $12.02(10.66-13.38)$ & $\begin{array}{l}2.80(2.44- \\
\quad 3.21)\end{array}$ & $\begin{array}{c}< \\
0.001\end{array}$ & $\begin{array}{l}2.70(2.31- \\
\quad 3.15)\end{array}$ & $\begin{array}{c}< \\
0.001\end{array}$ \\
\hline \multicolumn{9}{|l|}{ Sex } \\
\hline Male & 38,957 & 2,481 & $33,799.71$ & $7.34(7.06-7.62)$ & Reference & & Reference & \\
\hline Female & 19,158 & 554 & $17,267.19$ & $3.21(2.95-3.47)$ & $\begin{array}{l}0.44(0.40- \\
0.48)\end{array}$ & $\begin{array}{c}< \\
0.001\end{array}$ & $\begin{array}{l}0.55(0.50- \\
0.60)\end{array}$ & $\begin{array}{c}< \\
0.001\end{array}$ \\
\hline \multicolumn{9}{|l|}{ Marital status } \\
\hline Married or cohabitation & 40,224 & 1,976 & $35,698.49$ & $5.54(5.30-5.77)$ & Reference & & Reference & \\
\hline Other & 17,891 & 1,059 & $15,368.41$ & $6.89(6.49-7.30)$ & $\begin{array}{c}1.23(1.14- \\
1.33)\end{array}$ & $\begin{array}{c}< \\
0.001\end{array}$ & $\begin{array}{l}1.20(1.11- \\
1.30)\end{array}$ & $\begin{array}{c}< \\
0.001\end{array}$ \\
\hline \multicolumn{9}{|l|}{ Route of HIV transmission } \\
\hline Heterosexual intercourse & 49,608 & 2,494 & $43,780.65$ & $5.70(5.48-5.91)$ & Reference & & Reference & \\
\hline Intravenous drug use & 5,954 & 440 & $4,994.46$ & $8.81(8.01-9.61)$ & $\begin{array}{c}1.52(1.37- \\
1.68)\end{array}$ & $\begin{array}{c}< \\
0.001\end{array}$ & $\begin{array}{c}1.27(1.14- \\
1.43)\end{array}$ & $\begin{array}{c}< \\
0.001\end{array}$ \\
\hline Homosexual intercourse & 925 & 12 & 866.24 & $1.39(0.62-2.15)$ & $\begin{array}{l}0.25(0.14- \\
0.44)\end{array}$ & $\begin{array}{c}< \\
0.001\end{array}$ & $\begin{array}{l}0.50(0.28- \\
0.88)\end{array}$ & 0.016 \\
\hline Other & 1,628 & 89 & $1,425.56$ & $6.24(4.98-7.51)$ & $\begin{array}{l}1.10(0.89- \\
1.36)\end{array}$ & 0.391 & $\begin{array}{l}1.03(0.83- \\
1.28)\end{array}$ & 0.774 \\
\hline \multicolumn{9}{|c|}{$\begin{array}{l}\text { CD4 cell count (cells } / \mu \mathrm{L}) \text { before } \\
\text { ART }\end{array}$} \\
\hline$<200$ & 34,774 & 2,622 & $30,201.91$ & $8.68(8.36-9.01)$ & Reference & & Reference & \\
\hline $200-350$ & 16,252 & 283 & $14,605.50$ & $1.94(1.72-2.16)$ & $\begin{array}{l}0.22(0.20- \\
0.25)\end{array}$ & $\begin{array}{c}< \\
0.001\end{array}$ & $\begin{array}{l}0.26(0.23- \\
0.30)\end{array}$ & $\begin{array}{c}< \\
0.001\end{array}$ \\
\hline $350-500$ & 4,550 & 48 & $4,076.29$ & $1.18(0.85-1.50)$ & $\begin{array}{l}0.14(0.10- \\
0.18)\end{array}$ & $\begin{array}{c}< \\
0.001\end{array}$ & $\begin{array}{l}0.19(0.14- \\
0.25)\end{array}$ & $\begin{array}{c}< \\
0.001\end{array}$ \\
\hline$\geq 500$ & 1,648 & 16 & $1,459.20$ & $1.10(0.57-1.62)$ & $\begin{array}{l}0.13(0.08- \\
\quad 0.21)\end{array}$ & $\begin{array}{c}< \\
0.001\end{array}$ & $\begin{array}{l}0.17(0.10- \\
0.27)\end{array}$ & $\begin{array}{c}< \\
0.001\end{array}$ \\
\hline Missing & 891 & 66 & 724.00 & $9.12(6.97-11.26)$ & $\begin{array}{c}1.03(0.81- \\
1.31)\end{array}$ & 0.824 & $\begin{array}{c}1.21(0.95- \\
1.55)\end{array}$ & 0.129 \\
\hline \multicolumn{9}{|l|}{ Initial ART regimen } \\
\hline $\begin{array}{l}\text { The first-line ART } \\
\text { containing D4T }\end{array}$ & 14,244 & 1,347 & $1,2276.66$ & $10.97(10.40-11.54)$ & Reference & & Reference & \\
\hline $\begin{array}{l}\text { The first-line ART } \\
\text { containing AZT }\end{array}$ & 23,059 & 791 & $20,389.98$ & $3.88(3.62-4.14)$ & $\begin{array}{l}0.35(0.32- \\
0.39)\end{array}$ & $\begin{array}{c}< \\
0.001\end{array}$ & $\begin{array}{l}0.53(0.49- \\
0.59)\end{array}$ & $\begin{array}{c}< \\
0.001\end{array}$ \\
\hline $\begin{array}{l}\text { The first-line ART } \\
\text { containing TDF }\end{array}$ & 13,965 & 547 & $12,508.72$ & $4.37(4.02-4.73)$ & $\begin{array}{l}0.40(0.36- \\
0.44)\end{array}$ & $\begin{array}{c}< \\
0.001\end{array}$ & $\begin{array}{l}0.70(0.62- \\
\quad 0.79)\end{array}$ & $\begin{array}{c}< \\
0.001\end{array}$ \\
\hline $\begin{array}{l}\text { The first-line ART } \\
\text { containing LPV/r }\end{array}$ & 4,510 & 263 & $3,765.83$ & $6.98(6.16-7.81)$ & $\begin{array}{l}0.63(0.55- \\
0.72)\end{array}$ & $\begin{array}{c}< \\
0.001\end{array}$ & $\begin{array}{l}1.02(0.88- \\
1.18)\end{array}$ & 0.837 \\
\hline Other & 2,337 & 87 & $2,125.71$ & $4.09(3.25-4.93)$ & $\begin{array}{l}0.38(0.31- \\
\quad 0.47)\end{array}$ & $\begin{array}{c}< \\
0.001\end{array}$ & $\begin{array}{l}0.40(0.32- \\
0.50)\end{array}$ & $\begin{array}{c}< \\
0.001\end{array}$ \\
\hline \multicolumn{9}{|l|}{ Level of ART site } \\
\hline Provincial & 10,920 & 475 & $9,810.33$ & $4.84(4.42-5.27)$ & Reference & & Reference & \\
\hline Prefecture & 22,525 & 953 & $20,001.78$ & $4.76(4.47-5.06)$ & $\begin{array}{l}0.98(0.88- \\
1.09)\end{array}$ & 0.718 & $\begin{array}{c}1.14(1.02- \\
1.28)\end{array}$ & 0.020 \\
\hline
\end{tabular}


TABLE 3: Continued.

\begin{tabular}{|c|c|c|c|c|c|c|c|c|}
\hline Variable & Number & Deaths & $\begin{array}{l}\text { Person- } \\
\text { years }\end{array}$ & $\begin{array}{l}\text { Deaths per } 100 \text { person-years } \\
(95 \% \mathrm{CI})\end{array}$ & $\begin{array}{l}\text { HR }(95 \% \\
\quad \text { CI })\end{array}$ & $P$ & $\begin{array}{l}\text { AHR }(95 \% \\
\text { CI) }\end{array}$ & $P$ \\
\hline County & 24,670 & 1,607 & $21,254.79$ & $7.56(7.20-7.92)$ & $\begin{array}{l}1.54(1.39- \\
1.71)\end{array}$ & $\begin{array}{c}< \\
0.001\end{array}$ & $\begin{array}{l}2.12(1.90- \\
2.37)\end{array}$ & $\begin{array}{c}< \\
0.001\end{array}$ \\
\hline \multicolumn{9}{|c|}{ Year of ART initiation } \\
\hline 2003-2008 & 7,741 & 656 & $6,865.09$ & $9.56(8.84-10.27)$ & Reference & & Reference & \\
\hline $2009-2011$ & 17,800 & 1,158 & $15,542.50$ & $7.45(7.03-7.87)$ & $\begin{array}{l}0.77(0.70- \\
0.85)\end{array}$ & $\begin{array}{c}< \\
0.001\end{array}$ & $\begin{array}{l}0.77(0.70- \\
0.86)\end{array}$ & $\begin{array}{c}< \\
0.001\end{array}$ \\
\hline $2012-2015$ & 32,574 & 1,221 & $28,659.32$ & $4.26(4.03-4.49)$ & $\begin{array}{l}0.44(0.40- \\
0.49)\end{array}$ & $\begin{array}{c}< \\
0.001\end{array}$ & $\begin{array}{l}0.49(0.43- \\
0.55)\end{array}$ & $\begin{array}{c}< \\
0.001\end{array}$ \\
\hline
\end{tabular}

ART: antiretroviral therapy; D4T: stavudine; AZT: azidothymidine; TDF: tenofovir; LPV/r: ritonavir-boosted lopinavir; HR: hazard ratio; AHR: adjusted hazard ratio.

mortality rate than males after ART initiation [28, 29].(Supplementary Tables 2 and 3). Previous studies have also demonstrated that there is a lower mortality rate among females after initiation of ART. It could be possibly attributed to better responses to drugs, early diagnosis, adherence to ART, and psychosocial factors in females [30]. Thus, interventions should be designed which are aimed at giving extra support to the groups with high mortality. The CD4 cell counts below 200 cells $/ \mu \mathrm{L}$ resulted in high mortality. Previous studies have shown a relationship among persons with CD4 cell counts below 200 cells $/ \mu \mathrm{L}$ developing drug-resistant viral strains that resulted in a higher risk of mortality [31]. Initiating ART at CD4 count cell $\geq 500$ can have a favorable outcome in reducing mortality [24, 32]. (Supplementary Table 4).

Mortality is also found to be high in county-level of ART sites than the provincial sites. This is supported by the fact that county and prefecture-level health care providers have cited adverse reaction, opportunistic infections, and other complications that resulted in the referral to the provincial centers [33]. The health care system at the county level in China has inadequate resources and few specialty doctors. The Chinese government is managing these inequalities in the distribution of health care. They are providing financial and professional incentives, rural training and recruitment, and administrative measures as intervention strategies to tackle disparities in health care [34]. The National Health Commission is providing incentives for doctors for treating HIV/AIDS-affected individuals and also providing fellowship that encourages specialists to provide care to patients and clinical training to allied health care workers in rural areas [33, 35]. In Guangxi, HIV cases are diagnosed late, and also, there is a delay in the initiation of free ART, due to the essential steps needed in providing care [7]. Simple steps in early diagnosing and initiating ART should be implemented that can help in early diagnosis of HIV, initiating treatment, and reducing the mortality rate.

The overall attrition rate was 8.66 per 100 person-years in HIV infected patients who started ART between January 2003 and June 2015. In most of the attrition, more than $56 \%$ occurred during the first year of ART initiation. A high attrition rate can result in suboptimal treatment results, an increase in mortality rate, increased cost of care, and further transmission of HIV [15]. A previous study conducted on ART in China has shown side effects from the treatment, patient self-request, and adherence issues as the top three reasons for attrition during ART [18]. It is also worthwhile to note that patients who were lost to follow-up might have different treatment outcomes compared to patients who remained in the study, such as high mortality and viral load rebound due to stop ART [36]. Nevertheless, a high attrition rate is worrisome and needs urgent attention. Attrition was high as the age increases, and men were more likely than females to experience attrition within the first year of ART initiation (Supplementary Table 6). Also, men have poor health-seeking behaviors than women that lead to more advanced disease when initiating ART. This adds to more mortality in men than in their counterparts [37]. The risk of attrition was also high among those individuals whose marital status was other than married or cohabitation, intravenous route of HIV transmission, county-level of ART site, and the year of ART initiation between the years 2012 and 2015.

The study has shown that both mortality and attrition are high among intravenous drug users than the sexual route. Past studies have shown that patients identified as intravenous drug users are less likely to seek care after HIV diagnosis and more likely to miss scheduled appointments, thus resulting in the loss in follow-up $[38,39]$ and attrition. Attrition in the county is higher than provincial and prefecture sites. Previous studies have demonstrated that attrition is high among peripheral health clinics than urban clinics, possibly due to the lack of capacity to manage complicated HIV cases [40]. The attrition rate is less among patients with low CD4 cell count (Supplementary Table 7), possibly because patients with lower CD4 cell counts are more likely to have AIDS symptoms; such individuals may have better compliance to ART [12].

In our study, the mortality rate was high in persons with first-line ART containing D4T followed by TDF. The attrition rate was high in persons with first-line ART containing $\mathrm{LPV} / \mathrm{r}$ followed by AZT. Past studies have shown that patients in resource-limited countries had first-line ART regimen failure [41]. However, patients who switch early to booster protease inhibitors (LPV/r) containing regimen have shown the effectiveness of the treatment due to early viral 
TABle 4: Attrition rate of the first year in PLHIV who started ART between 2003 and June 2015 in Guangxi, China.

\begin{tabular}{|c|c|c|c|c|c|c|c|c|}
\hline Variable & Number & Attritions & $\begin{array}{l}\text { Person- } \\
\text { years }\end{array}$ & $\begin{array}{l}\text { Attritions per } 100 \text { person-years } \\
(95 \% \mathrm{CI})\end{array}$ & $\begin{array}{l}\mathrm{HR}(95 \% \\
\mathrm{CI})\end{array}$ & $P$ & $\begin{array}{l}\text { AHR }(95 \% \\
\text { CI) }\end{array}$ & $P$ \\
\hline Total & 58,115 & 8,947 & $51,066.90$ & $17.52(17.17-17.87)$ & - & - & - & - \\
\hline \multicolumn{9}{|l|}{ Age (years) } \\
\hline $18-34$ & 18,358 & 2,424 & $16,591.47$ & $14.61(14.04-15.18)$ & Reference & & Reference & \\
\hline $35-49$ & 19,290 & 2,770 & $17,079.86$ & $16.22(15.63-16.81)$ & $\begin{array}{c}1.11(1.05- \\
1.17)\end{array}$ & $\begin{array}{c}< \\
0.001\end{array}$ & $\begin{array}{c}1.15(1.09- \\
1.22)\end{array}$ & $\begin{array}{c}< \\
0.001\end{array}$ \\
\hline $50-70$ & 17,457 & 2,958 & $15,016.71$ & $19.7(19.01-20.39)$ & $\begin{array}{l}1.35(1.28- \\
1.42)\end{array}$ & $\begin{array}{c}< \\
0.001\end{array}$ & $\begin{array}{c}1.55(1.46- \\
1.64)\end{array}$ & $\begin{array}{c}< \\
0.001\end{array}$ \\
\hline$\geq 70$ & 3,010 & 795 & $2,378.87$ & $33.42(31.15-35.68)$ & $\begin{array}{l}2.27(2.09- \\
2.46)\end{array}$ & $\begin{array}{c}< \\
0.001\end{array}$ & $\begin{array}{l}2.51(2.30- \\
2.73)\end{array}$ & $\begin{array}{c}< \\
0.001\end{array}$ \\
\hline \multicolumn{9}{|l|}{ Sex } \\
\hline Male & 38,957 & 6,284 & $33,799.71$ & $18.59(18.14-19.04)$ & Reference & & Reference & \\
\hline Female & 19,158 & 2,663 & $17,267.19$ & $15.42(14.85-15.99)$ & $\begin{array}{l}0.83(0.79- \\
0.87)\end{array}$ & $\begin{array}{c}< \\
0.001\end{array}$ & $\begin{array}{l}0.89(0.85- \\
0.94)\end{array}$ & $\begin{array}{c}< \\
0.001\end{array}$ \\
\hline \multicolumn{9}{|l|}{ Marital status } \\
\hline Married or cohabitation & 40,224 & 5,697 & $35,698.49$ & $15.96(15.55-16.36)$ & Reference & & Reference & \\
\hline Other & 17,891 & 3,250 & $15,368.41$ & $21.15(20.44-21.86)$ & $\begin{array}{l}1.32(1.27- \\
1.38)\end{array}$ & $\begin{array}{c}< \\
0.001\end{array}$ & $\begin{array}{l}1.32(1.26- \\
1.38)\end{array}$ & $\begin{array}{c}< \\
0.001\end{array}$ \\
\hline \multicolumn{9}{|l|}{ Route of HIV transmission } \\
\hline Heterosexual intercourse & 49,608 & 7,357 & $43,780.65$ & $16.80(16.43-17.18)$ & Reference & & Reference & \\
\hline Intravenous drug use & 5,954 & 1,289 & $4,994.46$ & $25.81(24.43-27.18)$ & $\begin{array}{c}1.53(1.44- \\
1.62)\end{array}$ & $\begin{array}{c}< \\
0.001\end{array}$ & $\begin{array}{l}1.87(1.75- \\
2.00)\end{array}$ & $\begin{array}{c}< \\
0.001\end{array}$ \\
\hline Homosexual intercourse & 925 & 66 & 866.24 & $7.62(5.83-9.41)$ & $\begin{array}{l}0.45(0.36- \\
0.58)\end{array}$ & $\begin{array}{c}< \\
0.001\end{array}$ & $\begin{array}{l}0.45(0.35- \\
0.58)\end{array}$ & $\begin{array}{c}< \\
0.001\end{array}$ \\
\hline Other & 1,628 & 235 & $1,425.56$ & $16.48(14.43-18.54)$ & $\begin{array}{c}0.98(0.86- \\
1.12)\end{array}$ & 0.783 & $\begin{array}{c}1.08(0.95- \\
1.23)\end{array}$ & 0.226 \\
\hline \multicolumn{9}{|l|}{$\begin{array}{l}\mathrm{CD} 4 \text { cell count }(\text { cells } / \mu \mathrm{L}) \\
\text { before ART }\end{array}$} \\
\hline$<200$ & 34,774 & 5,030 & $30,201.91$ & $16.65(16.21-17.10)$ & Reference & & Reference & \\
\hline $200-350$ & 16,252 & 2,598 & $14,605.50$ & $17.79(17.12-18.45)$ & $\begin{array}{l}1.07(1.02- \\
1.12)\end{array}$ & 0.006 & $\begin{array}{l}1.01(0.96- \\
1.06)\end{array}$ & 0.765 \\
\hline $350-500$ & 4,550 & 783 & $4,076.29$ & $19.21(17.90-20.52)$ & $\begin{array}{l}1.15(1.07- \\
1.24)\end{array}$ & $\begin{array}{c}< \\
0.001\end{array}$ & $\begin{array}{l}1.11(1.03- \\
1.21)\end{array}$ & 0.007 \\
\hline$\geq 500$ & 1,648 & 321 & $1,459.20$ & $22.00(19.65-24.34)$ & $\begin{array}{l}1.32(1.18- \\
1.48)\end{array}$ & $\begin{array}{c}< \\
0.001\end{array}$ & $\begin{array}{l}1.29(1.15- \\
1.45)\end{array}$ & $\begin{array}{c}< \\
0.001\end{array}$ \\
\hline Missing & 891 & 215 & 724.00 & $29.70(25.83-33.57)$ & $\begin{array}{l}1.78(1.55- \\
2.04)\end{array}$ & $\begin{array}{c}< \\
0.001\end{array}$ & $\begin{array}{c}1.62(1.41- \\
1.86)\end{array}$ & $\begin{array}{c}< \\
0.001\end{array}$ \\
\hline \multicolumn{9}{|l|}{ Initial ART regimen } \\
\hline $\begin{array}{l}\text { The first-line ART } \\
\text { containing D4T }\end{array}$ & 14,244 & 1,922 & $12,276.66$ & $15.66(14.97-16.34)$ & Reference & & Reference & \\
\hline $\begin{array}{l}\text { The first-line ART } \\
\text { containing AZT }\end{array}$ & 23,059 & 3,845 & $20,389.98$ & $18.86(18.28-19.44)$ & $\begin{array}{c}1.20(1.14- \\
1.27)\end{array}$ & $\begin{array}{c}< \\
0.001\end{array}$ & $\begin{array}{c}1.09(1.03- \\
1.16)\end{array}$ & 0.003 \\
\hline $\begin{array}{l}\text { The first-line ART } \\
\text { containing TDF }\end{array}$ & 13,965 & 1,935 & $12,508.72$ & $15.47(14.80-16.14)$ & $\begin{array}{c}0.99(0.93- \\
1.05)\end{array}$ & 0.734 & $\begin{array}{l}0.81(0.75- \\
0.87)\end{array}$ & $\begin{array}{c}< \\
0.001\end{array}$ \\
\hline $\begin{array}{l}\text { The first-line ART } \\
\text { containing LPV/r }\end{array}$ & 4,510 & 1,004 & $3,765.83$ & $26.66(25.05-28.27)$ & $\begin{array}{c}1.70(1.57- \\
1.83)\end{array}$ & $\begin{array}{c}< \\
0.001\end{array}$ & $\begin{array}{c}1.34(1.23- \\
1.46)\end{array}$ & $\begin{array}{c}< \\
0.001\end{array}$ \\
\hline Other & 2,337 & 241 & $2,125.71$ & $11.34(9.94-12.73)$ & $\begin{array}{c}0.73(0.64- \\
0.83)\end{array}$ & $\begin{array}{c}< \\
0.001\end{array}$ & $\begin{array}{c}0.87(0.76- \\
1.00)\end{array}$ & 0.044 \\
\hline \multicolumn{9}{|l|}{ Level of ART site } \\
\hline Provincial & 10,920 & 1,470 & $9,810.33$ & $14.98(14.24-15.73)$ & Reference & & Reference & \\
\hline Prefecture & 22,525 & 3,378 & $20,001.78$ & $16.89(16.33-17.44)$ & $\begin{array}{c}1.13(1.06- \\
1.20)\end{array}$ & $\begin{array}{c}< \\
0.001\end{array}$ & $\begin{array}{c}1.02(0.96- \\
1.08)\end{array}$ & 0.593 \\
\hline
\end{tabular}


TABLE 4: Continued.

\begin{tabular}{|c|c|c|c|c|c|c|c|c|}
\hline Variable & Number & Attritions & $\begin{array}{l}\text { Person- } \\
\text { years }\end{array}$ & $\begin{array}{l}\text { Attritions per } 100 \text { person-years } \\
(95 \% \mathrm{CI})\end{array}$ & $\begin{array}{l}\mathrm{HR}(95 \% \\
\quad \mathrm{CI})\end{array}$ & $P$ & $\begin{array}{l}\text { AHR }(95 \% \\
\text { CI })\end{array}$ & $P$ \\
\hline County & 24,670 & 4,099 & $21,254.79$ & $19.29(18.71-19.86)$ & $\begin{array}{l}1.29(1.21- \\
1.36)\end{array}$ & $\begin{array}{c}< \\
0.001\end{array}$ & $\begin{array}{l}1.04(0.98- \\
1.11)\end{array}$ & 0.178 \\
\hline \multicolumn{9}{|c|}{ Year of ART initiation } \\
\hline 2003-2008 & 7,741 & 694 & $6,865.09$ & $10.11(9.38-10.84)$ & Reference & & Reference & \\
\hline 2009-2011 & 17,800 & 2,813 & $15,542.50$ & $18.1(17.45-18.75)$ & $\begin{array}{l}1.78(1.64- \\
1.93)\end{array}$ & $\begin{array}{c}< \\
0.001\end{array}$ & $\begin{array}{l}1.74(1.60- \\
1.91)\end{array}$ & $\begin{array}{c}< \\
0.001\end{array}$ \\
\hline 2012-2015 & 32,574 & 5,440 & $28,659.32$ & $18.98(18.49-19.47)$ & $\begin{array}{l}1.87(1.73- \\
2.02)\end{array}$ & $\begin{array}{c}< \\
0.001\end{array}$ & $\begin{array}{l}1.90(1.73- \\
2.08)\end{array}$ & $\begin{array}{c}< \\
0.001\end{array}$ \\
\hline
\end{tabular}

ART: antiretroviral therapy; D4T: stavudine; AZT: azidothymidine; TDF: tenofovir; LPV/r: ritonavir-boosted lopinavir; HR: hazard ratio; AHR: adjusted hazard ratio.

suppression. Since the majority of these patients reside and seek ART in rural areas (prefecture and county) that had no prior exposure to protease inhibitors [42], the viral suppression depends on the adherence. A large study in South Africa has shown that PLHIV without prior exposure to protease inhibitors had shown that viral failure with boosted protease inhibitors is barely coupled with the surfacing of new protease mutations [43]. Since in our study the attrition is high among persons with first-line ART containing LPV/r, we can conclude that lack of adherence to protease inhibitors is a primary cause of high attrition. Also, the past studies have well documented gastrointestinal side effects during the initial therapy with LPV/r than the other protease inhibitors $[44,45]$. This can, in turn, lead to high attrition among the LPV/r users. Future studies should be directed towards the areas with resource-limited settings that should perform population-level adherence to protease inhibitors as part of the nationwide treatment programs and also use of other protease inhibitors with better gastrointestinal tolerability and less adverse effects. Continued improvement in the quality of HIV treatment and care is needed to further reduce the mortality rate and attrition rate in Chinese patients.

There are a few limitations to the study. Firstly, some patients in the study were missing $\mathrm{CD} 4{ }^{+}$cell count data, which is an important risk factor for attrition. There is a likelihood that the missing $\mathrm{CD}^{+}$cell count data will differ from the patients with complete data. To compensate this, a missing $\mathrm{CD}^{+}$cell count category has been added to the analysis. Secondly, there is likely bias due to residual confounding. Many potential confounding variables could not be included in the cause-specific Cox proportional hazard models because the data was collected at the time of diagnosis of HIV, which is much later than the disease occurrence. Only a few variables like age, gender, and route of HIV transmission were unchanged at the time of HIV infection; hence, they can be included in the analysis. Thirdly, the study outcomes included death and attrition (cessation of ART or loss to follow-up). The reasons for attrition of cessation of ART and loss to follow-up are different. Death might be unreported, due to high attrition of loss to follow-up. Also, we need to note that the data collected from 2003 are the reflection of real-world treatment realities in a resource-limited setting. Such observational data can have possible inherent biases.
In conclusion, China's ART has clearly demonstrated reduced HIV mortality and attrition over the years. The mortality and attrition rates were both at the highest level in the first year of post-ART and declined year by year. So it is very important to strengthen the PLHIV management before ART and the first year post-ART. Additionally, with the constantly increasing of PLHIV's CD4 level before ART, it is necessary to focus on their management to avoid attrition. As the NFATP is expanding in rural areas, intensive efforts are needed to tackle the inequalities in health care, improve and increase drug supply, and ensure the proper training of health care workers and availability of specialists to treat PLHIV. Continued improvement in the quality of HIV treatment and care is needed to further reduce the mortality rate and attrition rate in Chinese patients.

\section{Abbreviations \\ D4T: Stavudine \\ AZT: Azidothymidine \\ TDF: Tenofovir \\ LPV/r: Ritonavir-boosted lopinavir \\ AHR: Adjusted hazard ratio \\ HR: Hazard ratio.}

\section{Data Availability}

All data supporting the findings of this study are available within the paper and its supplementary information file. The raw data are not publicly available due to governmental regulation.

\section{Additional Points}

Strengths and Limitations of This Study. (i) This is an observational cohort study in Guangxi, China, including 58,115 PLHIV. (ii) The large cohort provides strong evidence in support of our study results. (iii) Treatment effects of death and attrition were assessed through Cox proportional hazard models. (iv) This study might not be representative of all PLHIV in China. 


\section{Disclosure}

The funders of the study had no role in study design, data collection, data analysis, data interpretation, or writing of the paper.

\section{Conflicts of Interest}

The authors declare that they have no conflicts of interest.

\section{Authors' Contributions}

JZ, YA, YR, and LL were responsible for study design and planning. WY, QZ, ZS, GL, YC, and HC contributed to the data collection and management. JZ, YA, ZS, YR, and LL contributed to the data analysis. JZ, YA, WY, QZ, ZS, GL, YC, HC, WF, HX, YS, YR, and LL contributed to the interpretation. JZ, YA, WY, QZ, ZS, GL, YC, HC, WF, HX, YS, YR, and LL contributed to writing the report. All authors read and approved the final version of the paper. The corresponding author has full access to all data in the study and takes final responsibility for the decision to submit for publication. Data in this manuscript were collected by the Guangxi Center for Disease Control and Prevention. The principal investigators for this study included Z. S., G. L., and Q. Z. (Guangxi Center for Disease Control and Prevention).

\section{Acknowledgments}

This study was supported by the Guangxi Medical and Health Project (Z20170126), the National Natural Science Foundation of China (Grants 11971479, 81502862, 81460510, 81360442, and 91546203), Guangxi Science and Technology Bureau (Grant AB16380213), Guangxi Bagui Honor Scholarship, Ministry of Science and Technology of China (2018ZX10721102006, 2017ZX10201101), Guangxi Key Laboratory of AIDS Prevention Control and Translation and Chinese State Key Laboratory of Infectious Disease Prevention and Control.

\section{Supplementary Materials}

Supplementary figure 1. Enrollment, and Follow-up of the Study Participants. Supplementary table 1. Mortality rates of patients with HIV who started ART between 2003 and June 2015 in Guangxi, China. Supplementary table 2. Mortality rates of the first year in patients with HIV who started ART between 2003 and June 2015 in Guangxi, China. Supplementary table 3. Mortality rates of the first year in patients with HIV who started ART between 2012 and June 2015 in Guangxi, China. Supplementary table 4. Mortalityrates of the first year in patients with HIV who started ART between 2003 and June 2015 in Guangxi, China, by CD4 count before ART. Supplementary table 5. Mortality rates of patients with HIV who started ART between 2003 and June 2015 in Guangxi, China. Supplementary table 6. Attrition rates of the first year in patients with HIV who started ART between 2003 and June 2015 in Guangxi, China. Supplementary table 7. Attrition rates of the first year in patients with HIV who started ART between 2003 and June 2015 in Guangxi, China, by CD4 count before ART. (Supplementary Materials)

\section{References}

[1] L. Guanghua, C. Yi, T. Shuai et al., "HIV, syphilis and behavioral risk factors among men who have sex with men in a drug-using area of southwestern China: results of 3 crosssectional surveys from 2013 to 2015," Medicine, vol. 97, no. 16, article e0404, 2018.

[2] W. Fan, R. Lu, G. Wu et al., "Alcohol drinking and HIVrelated risk among men who have sex with men in Chongqing, China," Alcohol, vol. 50, pp. 1-7, 2016.

[3] Y. Zhu, J. Liu, and B. Qu, "Psychometric properties of the Chinese version of the WHOQOL-HIV BREF to assess quality of life among people living with HIV/AIDS: a cross-sectional study," BMJ Open, vol. 7, no. 8, article e016382, 2017.

[4] L. L. Sabin, M. Bachman DeSilva, C. J. Gill et al., "Improving adherence to antiretroviral therapy with triggered Real-time text message Reminders," JAIDS Journal of Acquired Immune Deficiency Syndromes, vol. 69, no. 5, pp. 551-559, 2015.

[5] L. Ren, J. Li, S. Zhou et al., "Prognosis of HIV patients receiving antiretroviral therapy according to CD4 counts: a longterm follow-up study in Yunnan, China," Scientific Reports, vol. 7, no. 1, article 9595, 2017.

[6] Z. Dou, R. Y. Chen, Z. Wang et al., "HIV-infected former plasma donors in rural Central China: From infection to survival outcomes, 1985-2008," PLoS One, vol. 5, no. 10, article e13737, 2010.

[7] Z. Wu, Y. Zhao, X. Ge et al., "Simplified HIV testing and treatment in China: Analysis of mortality rates before and after a structural intervention," PLoS Medicine, vol. 12, no. 9, article e1001874, 2015.

[8] Y. Ma, Z. Dou, W. Guo et al., "The human immunodeficiency virus care continuum in China: 1985-2015," Clinical Infectious Diseases, vol. 66, no. 6, pp. 833-839, 2018.

[9] P. Liu, Z. Tang, G. Lan et al., "Early antiretroviral therapy on reducing HIV transmission in China: strengths, weaknesses and next focus of the program," Scientific Reports, vol. 8, no. 1, p. 3431, 2018.

[10] Z. Shen, Q. Zhu, Z. Tang et al., "Effects of CD4 cell counts and viral load testing on mortality rates in Patients with HIV infection receiving antiretroviral treatment: an observational cohort study in rural southwest China," Clinical Infectious Diseases, vol. 63, no. 1, pp. 108-114, 2016.

[11] R. Kang, L. Luo, H. Chen et al., “Treatment outcomes of initial differential antiretroviral regimens among HIV patients in Southwest China: comparison from an observational cohort study," BMJ Open, vol. 9, no. 3, article e025666, 2019.

[12] Z. Tang, S. W. Pan, Y. Ruan et al., "Effects of high CD4 cell counts on death and attrition among HIV patients receiving antiretroviral treatment: an observational cohort study," Scientific Reports, vol. 7, no. 1, 2017.

[13] Antiretroviral Therapy (ART) Cohort Collaboration, "HIV treatment response and prognosis in Europe and North America in the first decade of highly active antiretroviral therapy: a collaborative analysis," The Lancet, vol. 368, no. 9534, pp. 451458, 2006.

[14] M. E. Kruk, A. D. Gage, N. T. Joseph, G. Danaei, S. GarcíaSaisó, and J. A. Salomon, "Mortality due to low-quality health systems in the universal health coverage era: a systematic analysis of amenable deaths in 137 countries," The Lancet, vol. 392, no. 10160, pp. 2203-2212, 2018.

[15] H. Zhu, S. Napravnik, J. Eron et al., “Attrition among human immunodeficiency virus (HIV)-infected patients initiating 
antiretroviral therapy in China, 2003-2010," PLoS One, vol. 7, no. 6, article e39414, 2012.

[16] F. Zhang, Z. Dou, Y. Ma et al., "Five-year outcomes of the China national free antiretroviral treatment program," Annals of Internal Medicine, vol. 151, no. 4, pp. 241-251, 2009.

[17] S. Liang, Z. Shen, J. Yan et al., "Low virologic failure and drug resistance among HIV-infected patients receiving hospitalbased ART while care and outreach through community in Guangxi, China," Frontiers in Public Health, vol. 3, 2015.

[18] Y. Ma, F. Zhang, Y. Zhao et al., "Cohort profile: the Chinese national free antiretroviral treatment cohort," International Journal of Epidemiology, vol. 39, no. 4, pp. 973-979, 2010.

[19] F. J. Zhang, J. Pan, L. Yu, Y. Wen, and Y. Zhao, "Current progress of China's free ART program," Cell Research, vol. 15, no. 11-12, pp. 877-882, 2005.

[20] World Health Organization, Consolidated guidelines on the use of antiretroviral drugs for treating and preventing HIV infection: recommendations for a public health approach, World Health Organization, 2016.

[21] Z. Jia, Y. Mao, F. Zhang et al., "Antiretroviral therapy to prevent HIV transmission in serodiscordant couples in China (2003-11): a national observational cohort study," The Lancet, vol. 382, no. 9899, pp. 1195-1203, 2013.

[22] G. Somi, S. C. Keogh, J. Todd et al., "Low mortality risk but high loss to follow-up among patients in the Tanzanian national HIV care and treatment programme," Tropical Medicine \& International Health, vol. 17, no. 4, pp. 497-506, 2012.

[23] H. Zhu, S. Napravnik, J. J. Eron et al., "Decreasing excess mortality of HIV-infected patients initiating antiretroviral therapy: comparison with mortality in general population in China, 2003-2009," JAIDS Journal of Acquired Immune Deficiency Syndromes, vol. 63, no. 5, pp. e150-e157, 2013.

[24] M. C. Marazzi, G. Liotta, P. Germano et al., "Excessive early mortality in the first year of treatment in HIV type 1infected patients initiating antiretroviral therapy in resourcelimited settings," AIDS Research and Human Retroviruses, vol. 24, no. 4, pp. 555-560, 2008.

[25] S. Swaminathan, C. Padmapriyadarsini, L. Yoojin et al., "Nutritional supplementation in HIV-infected individuals in South India: a prospective interventional study," Clinical Infectious Diseases, vol. 51, no. 1, pp. 51-57, 2010.

[26] HIV-CAUSAL Collaboration, M. Ray, R. Logan et al., "The effect of combined antiretroviral therapy on the overall mortality of HIV-infected individuals," AIDS, vol. 24, no. 1, pp. 123-137, 2010.

[27] N. F. Önen, E. T. Overton, W. Seyfried et al., "Aging and HIV infection: a comparison between older HIV-infected persons and the general population," HIV Clinical Trials, vol. 11, no. 2, pp. 100-109, 2015.

[28] M. Maskew, A. T. Brennan, A. P. MacPhail, I. M. Sanne, and M. P. Fox, "Poorer ART outcomes with increasing age at a large public sector HIV clinic in Johannesburg, South Africa," Journal of the International Association of Physicians in AIDS Care, vol. 11, no. 1, pp. 57-65, 2011.

[29] A. F. Auld, F. Mbofana, R. W. Shiraishi et al., "Four-year treatment outcomes of adult patients enrolled in Mozambique's rapidly expanding antiretroviral therapy program," PLoS One, vol. 6, no. 4, article e18453, 2011.

[30] Z. Dou, J. Xu, J. H. Jiao et al., "Gender difference in 2-year mortality and immunological response to ART in an HIVinfected Chinese population, 2006-2008," PLoS One, vol. 6, no. 8, article e22707, 2011.
[31] E. J. Mills, C. Bakanda, J. Birungi, S. Yaya, N. Ford, and TASOCAN Writing Group, “The prognostic value of baseline CD4+ cell count beyond 6 months of antiretroviral therapy in HIVpositive patients in a resource-limited setting," AIDS, vol. 26, no. 11, pp. 1425-1429, 2012.

[32] UK Collaborative HIV Cohort (CHIC) Study Steering Committee, "Rate of AIDS diseases or death in HIV-infected antiretroviral therapy-naive individuals with high CD4 cell count," AIDS, vol. 21, no. 13, pp. 1717-1721, 2007.

[33] F. Zhang, J. E. Haberer, Y. Wang et al., "The Chinese free antiretroviral treatment program: challenges and responses," AIDS, vol. 21, Supplement 8, pp. S143-S148, 2007.

[34] K. Zhou, X. Zhang, Y. Ding, D. Wang, Z. Lu, and M. Yu, "Inequality trends of health workforce in different stages of medical system reform (1985-2011) in China," Human Resources for Health, vol. 13, no. 1, pp. 1-8, 2015.

[35] W. Huang, H. Long, J. Li et al., "Delivery of public health services by community health workers (CHWs) in primary health care settings in China: a systematic review (1996-2016)," Global Health Research and Policy, vol. 3, no. 1, 2018.

[36] M. Hull, M. Loutfy, W. Zhang et al., Persistent low-level viremia is associated with increased risk of virologic failure and mortality, San Francisco, 2010.

[37] M. Cornell, M. Schomaker, D. B. Garone et al., "Gender differences in survival among adult patients starting antiretroviral therapy in South Africa: a multicentre cohort study," PLoS Medicine, vol. 9, no. 9, article e1001304, 2012.

[38] R. P. Westergaard, T. Hess, J. Astemborski, S. H. Mehta, and G. D. Kirk, "Longitudinal changes in engagement in care and viral suppression for HIV-infected injection drug users," AIDS, vol. 27, no. 16, pp. 2559-2566, 2013.

[39] J. A. Fleishman, B. R. Yehia, R. D. Moore, P. T. Korthuis, K. A. Gebo, and HIV Research Network, "Establishment, retention, and loss to follow-up in outpatient HIV care," JAIDS Journal of Acquired Immune Deficiency Syndromes, vol. 60, no. 3, pp. 249-259, 2012.

[40] L. Molfino, A. M. Kumar, P. Isaakidis et al., "High attrition among HIV-infected patients with advanced disease treated in an intermediary referral center in Maputo, Mozambique," Global Health Action, vol. 7, no. 1, p. 23758, 2014.

[41] R. Kantor, L. Diero, A. DeLong et al., "Misclassification of firstline antiretroviral treatment failure based on immunological monitoring of HIV infection in resource-limited settings," Clinical Infectious Diseases, vol. 49, no. 3, pp. 454-462, 2009.

[42] Y. Ma, D. Zhao, L. Yu et al., "Predictors of virologic failure in HIV-1-infected adults receiving first-line antiretroviral therapy in 8 provinces in China," Clinical Infectious Diseases, vol. 50, no. 2, pp. 264-271, 2010.

[43] E. Lathouwers, S. De Meyer, I. Dierynck et al., "Virological characterization of patients failing darunavir/ritonavir or lopinavir/ritonavir treatment in the ARTEMIS study: 96-week analysis," Antiviral Therapy, vol. 16, no. 1, pp. 99-108, 2011.

[44] N. Clumeck, C. Mwamba, K. Kabeya et al., "First-line antiretroviral therapy with nevirapine versus lopinavir-ritonavir based regimens in a resource-limited setting," AIDS, vol. 28, no. 8, pp. 1143-1153, 2014.

[45] S. Naggie and C. Hicks, "Protease inhibitor-based antiretroviral therapy in treatment-naive HIV-1-infected patients: the evidence behind the options," Journal of Antimicrobial Chemotherapy, vol. 65, no. 6, pp. 1094-1099, 2010. 